\title{
Água e esgoto: \\ Embelezamento e higiene nas residências de Bauru-SP
}

Water and sewage:

Beautification and hygiene in the residences of Bauru-SP

Agua y alcantarillado:

Embellecimiento e higiene en las residencias de Bauru-SP

Érica Lemos Gulinelli Doutoranda do POSURB-ARQ, PUC Campinas/SP ericagulinelliarq@gmail.com

\section{Nilson Ghirardello}

Professor Assistente Doutor do PPGARQ, FAAC, UNESP Campus Bauru/SP

nghir@faac.unesp.br 


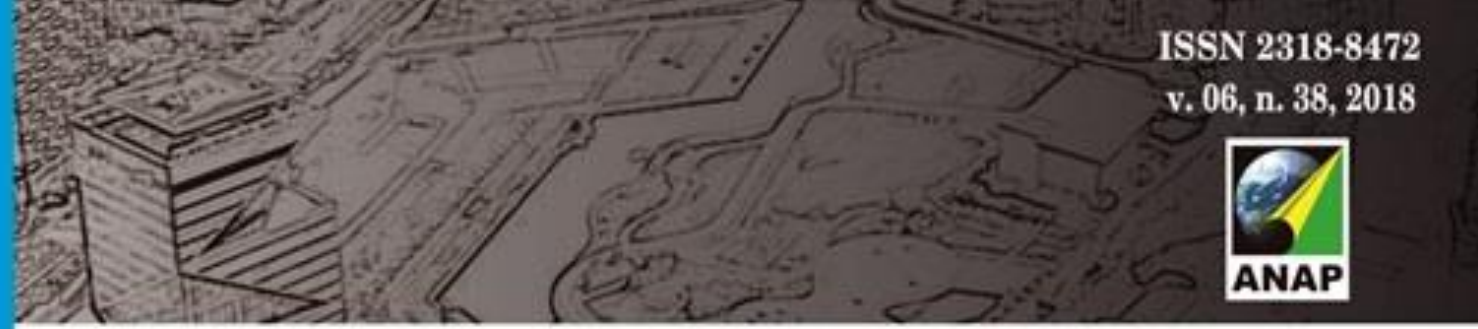

Gerenciamento de Cidades

\section{RESUMO}

Os discursos higienistas e de embelezamento urbano, juntamente com os códigos de posturas vigentes, nortearam a produção da moradia na cidade de Bauru-SP das décadas de 1900 a 1920 . A infraestrutura de água e esgoto foi um meio de minimizar as questões relacionadas com a higiene da moradia e da cidade. $O$ artigo tem como objetivo investigar os cômodos de serviços, principalmente os banheiros, na configuração dos espaços de morar, bem como entender a influência do saneamento nos projetos residenciais. A metodologia compreende: abordagem teórica sobre formação urbana, ferrovia, sanitarismo, infraestrutura e legislação; pesquisa em documentos primários; investigação e análise iconográfica em processos de aprovação para construção da edificação, que continham plantas e peças gráficas, localizados na prefeitura municipal. Como resultado, pretende elucidar questões acerca do saneamento visto como medida higienizadora e de embelezamento do ambiente construído, com a finalidade de prevenção de doenças e assepsia; compreender o diálogo entre as políticas sanitárias e habitacionais, por meio das análises das plantas aprovadas no município localizado no centro oeste paulista; e contribuir com estudos sobre história urbana.

Palavras-chave: Saneamento. Moradia. Infraestrutura.

\section{ABSTRACT}

The hygienist and urban beautification discourses, together with the codes of current positions, guided the production of housing in the city of Bauru-SP from the 1900s to the 1920s. Water and sewage infrastructure was a means of minimizing issues related to hygiene of the dwelling and the city. The article aims to investigate the service rooms, especially the bathrooms, in the configuration of living spaces, as well as to understand the influence of sanitation in residential projects. The methodology includes: theoretical approach on urban formation, railroad, sanitation, infrastructure and legislation; research on primary documents; research and iconographic analysis in approval processes for construction of the building, which contained plans and graphic pieces, located in the city hall. As a result, it seeks to elucidate questions about sanitation as a hygienizing and embellishing measure of the built environment, for the purpose of disease prevention and asepsis; to understand the dialogue between sanitary and housing policies, through the analysis of approved plants in the city located in the center of São Paulo; and contribute with studies on urban history.

Keywords: Sanitation. Home. Infrastructure.

\section{RESUMEN}

Los discursos higienistas y de embellecimiento urbano, junto con los códigos de posturas vigentes, orientaron la producción de la vivienda en la ciudad de Bauru-SP de las décadas de 1900 a 1920. La infraestructura de agua y alcantarillado fue un medio de minimizar las cuestiones relacionadas higiene de la vivienda y de la ciudad. El artículo tiene como objetivo investigar las habitaciones de servicios, principalmente los baños, en la configuración de los espacios de vivienda, así como entender la influencia del saneamiento en los proyectos residenciales. La metodología comprende: abordaje teórico sobre formación urbana, ferrocarril, sanitarismo, infraestructura y legislación; investigación en documentos primarios; investigación y análisis iconográfico en procesos de aprobación para la construcción de la edificación, que contenían plantas y piezas gráficas, ubicadas en la municipalidad municipal. Como resultado, pretende elucidar cuestiones acerca del saneamiento visto como medida higienizadora y de embellecimiento del ambiente construido, con la finalidad de prevención de enfermedades y asepsia; comprender el diálogo entre las políticas sanitarias y habitacionales, por medio de los análisis de las plantas aprobadas en el municipio ubicado en el centro oeste paulista; $y$ contribuir con estudios sobre historia urbana

Palabras clave: Saneamiento. Casa. Infraestructura. 


\section{INTRODUÇÃO}

Não raro se tem a decepção de abrir uma torneira, na esperança de ver jorrar a lympha chrystaina, indispensável a uma infinidade de misteres, mas apenas um estrepitar grotesco dela, misturado a simples burrifos, ou um tênue fio tristonho e lento, atestam logo a tímida presença do precioso líquido no fundo do reservatório (O BAURU, 18 de abril de 1915).

Falta d'Água: o grande problema que assombrou Bauru durante décadas - muitas foram as vezes em que os jornais utilizaram estas palavras como chamada de suas matérias. A cidade vivia um antagonismo dos discursos da Modernização, Higienização e Embelezamento. O saneamento e a infraestrutura de abastecimento de água e esgotamento sanitário foram questões permanentes de ações da municipalidade. O saneamento e a questão das águas urbanas são problematizados, discutidos, analisados e considerados assuntos importantes atualmente para a gestão das cidades. No entanto, não são marcas exclusivas da contemporaneidade. No campo de estudo da história urbana percebemos preocupações com as águas desde a formação da urbe. No Brasil, a história do saneamento se confunde com a formação das cidades. No início o abastecimento de água era realizado por meio da coleta em bicas e fontes nos povoados que estavam se formando, assim como na Europa. As primeiras ações sanitaristas se resumiam a drenagem dos terrenos e a instalação de chafarizes nas cidades. Em Bauru seguiu-se o mesmo modelo.

É esta condição pretérita o assunto deste artigo, focando a formação urbana a partir de 1896 e, quando entre as décadas de 1910 e 1920, a cidade de Bauru passou por um processo de modernização pautado em ações higienistas, de melhoramentos e embelezamentos, norteados por códigos de Posturas Municipais, com a construção da 10 Estação de Tratamento de água. As iniciativas tiveram como finalidade equacionar os problemas surgidos e agravados devido ao rápido crescimento da urbe - o qual fora incentivado pelas atividades econômicas e intensificado com a instalação das três ferrovias: Estrada de Ferro Sorocabana, Companhia Estrada de Ferro Noroeste do Brasil e Companhia Paulista. Tais questões caracterizavam-se pela insalubridade das águas dos mananciais de abastecimento e problemas de coleta.

A implantação da infraestrutura urbana terá um papel essencial no quadro de melhorias da cidade, reduzindo as doenças crônicas que as assolavam com frequência. A implantação de água e esgoto e a drenagem e retificação dos córregos, fazendo-os fluir com maior rapidez e com isso evitando enchentes calamitosas, bem como o aterro de brejos, serão obras relativamente comuns nas cidades paulistas mais prosperas, demonstrando um bom grau de profilaxia urbana, ao menos para os seus setores mais nobres e para aqueles mais bem aquinhoados (GHIRARDELLO, 2010, p.183).

\section{FORMAÇÃO URBANA E A INFLUÊNCIA DA FERROVIA}

No início o lugarejo contava com casas edificadas na antiga estrada que ligava os sertões a Fortaleza e Lençóis, (atual Rua Araújo Leite) núcleos urbanos vizinhos. Segundo Ghirardello (1992), esta estrada situava-se em sentido norte-sul, próximo ao Ribeirão das Flores, no entanto em cota alta para evitar enchentes $^{1}$. Acreditando no crescimento da região, já que receberiam as estradas de ferro, pessoas de posses se deslocaram para estas terras onde se inicia (e iniciaram) a formação de grandes fazendas como: a

\footnotetext{
${ }^{1}$ Percebem-se indícios da preocupação com as águas pluviais no início do traçado urbano da cidade. Esta e outras questões de infraestrutura futuramente culminam na necessidade do saneamento para o "embelezamento" e higienização da cidade.
} 
do coronel Azarias Ferreira Leite e seu tio Baptista de Araújo Leite, chamada Aureópolis, a Val de Palmas, entre outras.

Nas lavouras, principalmente de café, centenas de imigrantes europeus vieram trabalhar e aos poucos foram adquirindo propriedades na vila de Bauru, onde se estabeleceram com casas e comércio (PELEGRINA, 1991). Neste mesmo período, muitos moradores do município de Fortaleza transferiram-se para o distrito de Bauru, contribuindo para a decadência da sede original do município em razão do crescimento do distrito.

A partir de 1 de agosto de 1896, Fortaleza passava a ser um distrito de paz de Bauru. A lei n. 428 de 1 de agosto de 1896 expressa: Art. 1 - "O município de Espírito Santo de Fortaleza passa a denominar-se Bauru, mudando-se a sua sede para esta última povoação".

Segundo Pelegrina (1991), no cotidiano bauruense do final do século XIX não existiam: eletricidade, ruas pavimentadas, água encanada, rede de esgoto, veículos automotores, trens, bandas, clubes, escolas e hospitais como nos centros mais adiantados.

Esta comunidade voltada para a economia agrícola modifica-se e se desenvolve com a aproximação dos trilhos da Sorocabana. E as mudanças estruturais começam a despontar neste distrito. Neste momento inicia-se a expansão urbana, além dos limites do patrimônio inicial e com ele todos os problemas oriundos do crescimento populacional desenfreado.

A vinda da ferrovia foi importante para o desenvolvimento econômico, social e urbano de Bauru (Castro, 1993). Pode-se considerar o momento de ruptura com o ambiente rural da então Vila de Bauru para a construção de uma cidade modernizada, embelezada e higienizada pelos trilhos do progresso que chegava, o ideal almejado pelas elites locais. Neste contexto podemos verificar a manifestação da Ideologia de Higiene (CHALHOUB, 2006) sobre este ambiente urbano, com a finalidade de sanear a cidade dos problemas da sujeira, das doenças e da pobreza.

O higienismo contribuiu para a proposta de novos planos urbanísticos em diversas cidades, por meio de abertura de vias, infraestrutura, redes de abastecimento de água e coleta de esgoto, com consequente aumento da poluição hídrica, motivados pela crescente urbanização e industrialização. (CONSTANTINO, 2005, p.42).

A ampliação da rede ferroviária foi fundamental no processo de ocupação e expansão, norteando o traçado da nova cidade que se formava. Verifica-se que a ferrovia possibilitou vida econômica estável ao futuro povoado, como também, garantiu acessibilidade e escoamento da produção, e influenciou nas alterações do desenho urbano do município de Bauru.

É importante ressaltar que na Europa as estradas de ferro eram construídas buscando interligar as cidades já consolidadas. No entanto, no Brasil, e em particular no oeste do estado de São Paulo, a ferrovia foi concebida como forma de ocupar o território, abrir lavouras de café e também formar cidades,

[...] na Europa a estrada de ferro procura a cidade, isto é, o centro demográfico e o núcleo econômico já formado e estratificado. Aqui no Brasil, por uma fatalidade do continente, é forçada a procurar o deserto. [...] Em vez de unir centros fabris e agrícolas de vida já intensa e muito próximos uns dos outros, como na Europa, o caminho de ferro foi entre nós um criador de cidades. (SILVA, 1957, p. 80).

\footnotetext{
${ }^{2}$ Disponível em: http://www.al.sp.gov.br/repositorio/legislacao/lei/1896/lei-428-01.08.1896.html
} 
As construções de residências deste período possuíam condições mínimas de higiene, com alguns dos preceitos higienistas, como insolação e ventilação em todos os cômodos, conforme estabelecidas por legislação dos códigos de posturas e o Código Sanitário de São Paulo de 1894. (Figura 1)

\footnotetext{
As vilas e cidades dessa época não dispunham de serviços urbanos relativos as redes de abastecimento d'água e esgoto, temas resolvidos no interior das casas urbanas pelo trabalho escravo: As cisternas d'água e os barris de dejeções, os famosos 'tigres', eram normais nestas casas. (Reis Filho, 1987)
}

Mesmo que a cidade não tenha sido formada no período da escravidão (visto que a cidade se emancipou em 1896), as classes mais pobres, formadas por trabalhadores acabavam por fazer este papel para as classes mais abastadas, em troca de um pequeno pagamento.

Em Bauru, as casas de porta e janela, alinhadas a rua e utilizadas desde o período colonial, possuíam praticamente o mesmo aspecto exterior de todas construções das regiões do Estado de São Paulo, pouco variando. Apresentavam planta retangular, com duas águas de telhado - uma caindo para a fachada e outra para os fundos - e dois oitões laterais. Outro aspecto comum era a ausência de banheiros internos, estes quando existiam, eram acréscimos no corpo da casa ou se localizavam no fundo do quintal, e por serem estruturas independentes da construção principal recebiam o nome de "casinha".

Neste contexto, pode-se entender que: "E nos quintais ficava a casinha - nas cidades sempre construídas sobre uma fossa negra". Além disto, tem-se que: "Parecem que eram evitadas as construções no fundo dos lotes. Além da "casinha" e de uma ou outra cozinha "suja" de fora, nada mais." (LEMOS, 1976, P. 126)

A descoberta das primeiras plantas enviadas a prefeitura para aprovação e encontradas nos arquivos, permitiu conhecer os usos e a espacialização dessas construções, datadas do início do século XX. Os desenhos são poucos, porém este material nos ajuda a entender o modo de vida deste período. Podemos perceber tipologias de padrão vernacular, ainda advindas da influência da migração mineira, do início da ocupação da cidade. Como não havia redes domiciliares de abastecimento de água e coleta de esgoto, dificilmente apresentavam instalações hidráulicas em cozinhas e banheiro.

Há, ainda, plantas aprovadas onde não consta a existência de banheiros dentro da casa. Quando há, é apenas um anexo no edifício, sendo que a porta é voltada para a área externa, já que neste período contava-se com as fossas. Os fortes odores e os problemas de higiene provenientes deste sistema, inviabilizavam a instalações de banheiros nas áreas intimas e sociais da casa. Outras plantas apresentam edículas com escavação no solo para dejetos. Nos processos encontrados não há desenho do terreno e desta forma não foi possível saber se havia a casinha (área destinada a banheiro) no fundo do lote.

A figura 2 apresenta o pedido de aprovação de residência de João Batista, a ser construída na Rua Pyrajuy, em 1911. A morada era dividida em 4 cômodos, sem banheiro. Este desenho apresenta as aberturas, como portas e janelas em todos os ambientes, elementos importantes para a higiene da residência. Um ponto importante é a apresentação do corte, indicando detalhes da tesoura do telhado e altura do pé direito. 


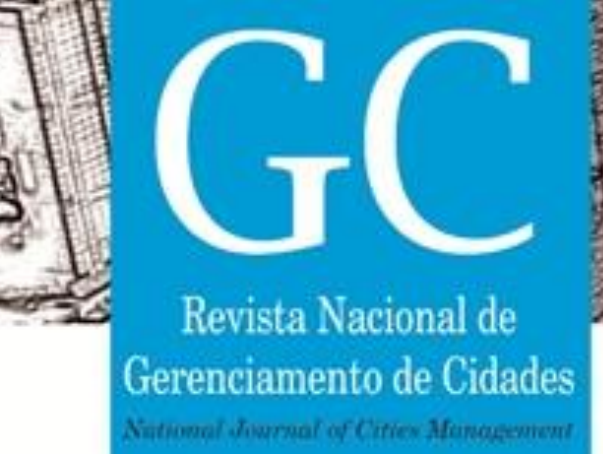

ISSN 2318-8472 v. 06, n. 38,2018

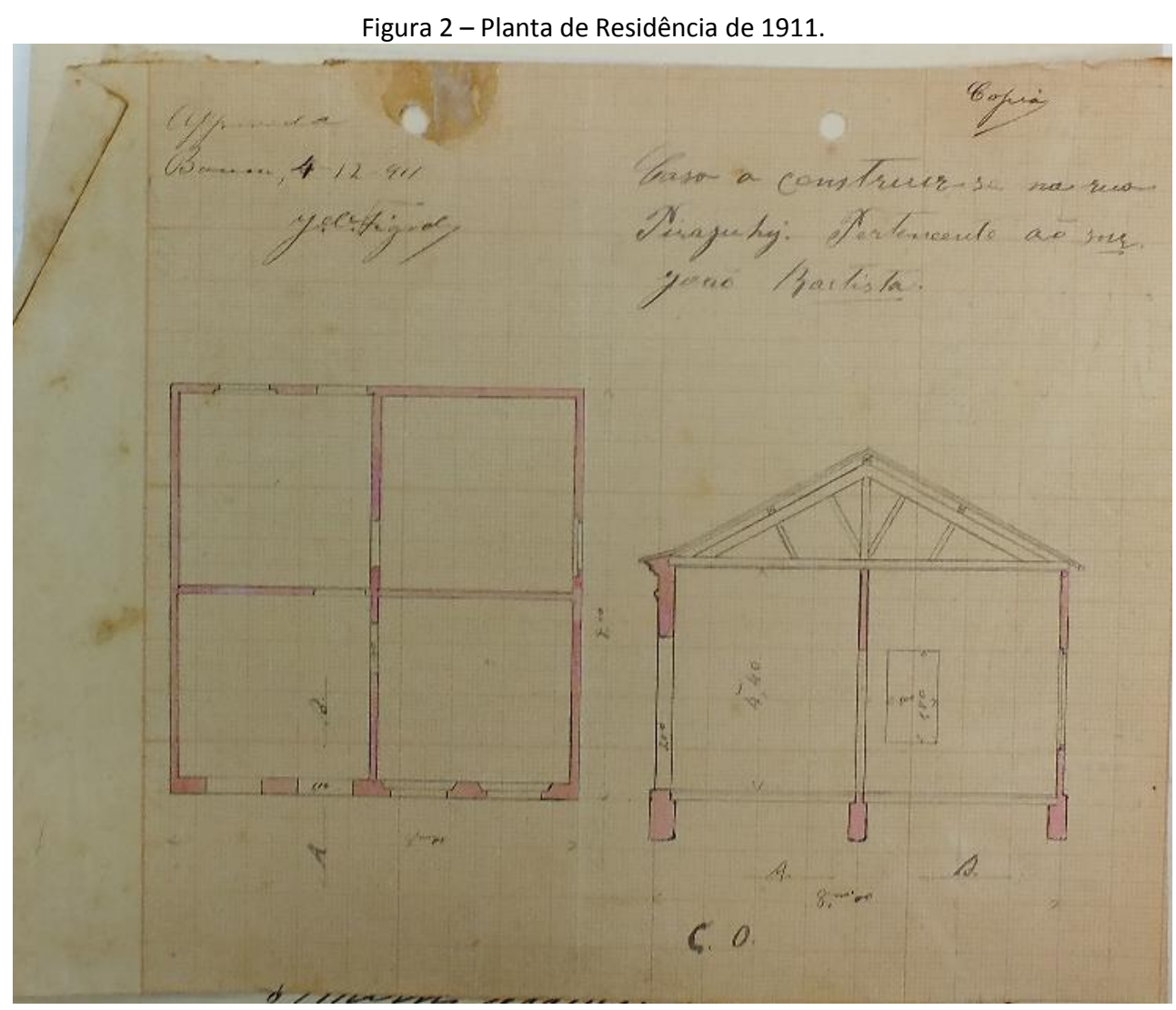

Fonte: arquivo SEPLAN -Prefeitura de Bauru), 2015.

É importante ressaltar que antes de 1911 a Prefeitura Municipal de Bauru não exigia aprovação de plantas para construção, como passou a ocorrer logo depois. A apresentação de projeto arquitetônico teve importância no que diz respeito ao controle no embelezamento urbano, além de ser importante instrumento de gerir as legislações municipais no tocante a higiene e estética construtiva na busca pela modernização da cidade.

Encontramos uma planta datada de 1912 (figura 3), já aprovada com a vigência do código de postura, e mesmo assim, não há a presença do banheiro no corpo da casa, o que demonstra a pouca atenção, ao menos de forma imediata, para a necessidade do cumprimento da lei. Importante salientar que a residência estava localizada onde passava rede de água e coleta de esgoto.

A proposta projetual de residência pertencia a Augusto da Costa Lopes, localizada na Rua Bandeirantes, esquina com a Gloria. Apresenta planta e corte indicando aberturas de portas e janelas, altura pé direito e tesoura do telhado. Outro aspecto ligado a higiene e conforto que a planta revela em seu desenho é o porão, que protege o piso assoalhado do contato com o solo e ao mesmo tempo ajuda a melhorar a temperatura interna da residência. 


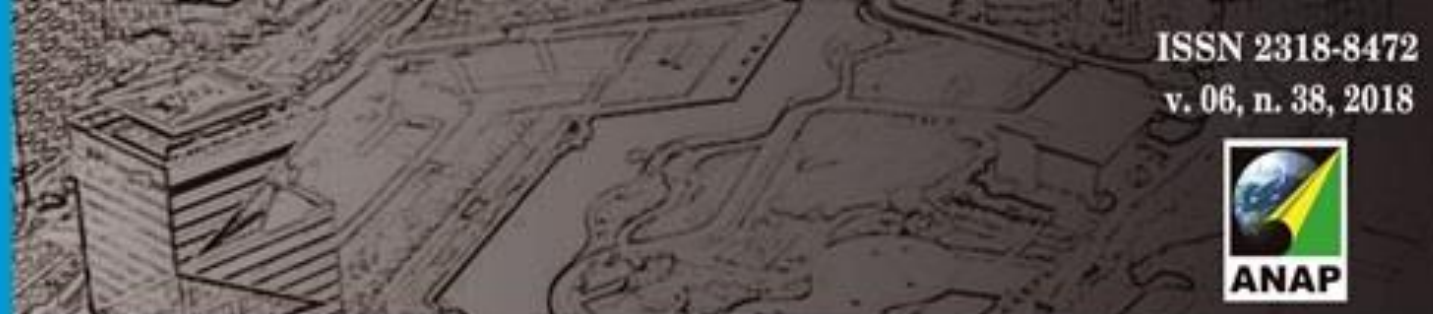

Revista Nacional de Gerenciamento de Cidades

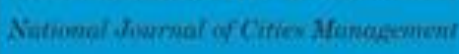

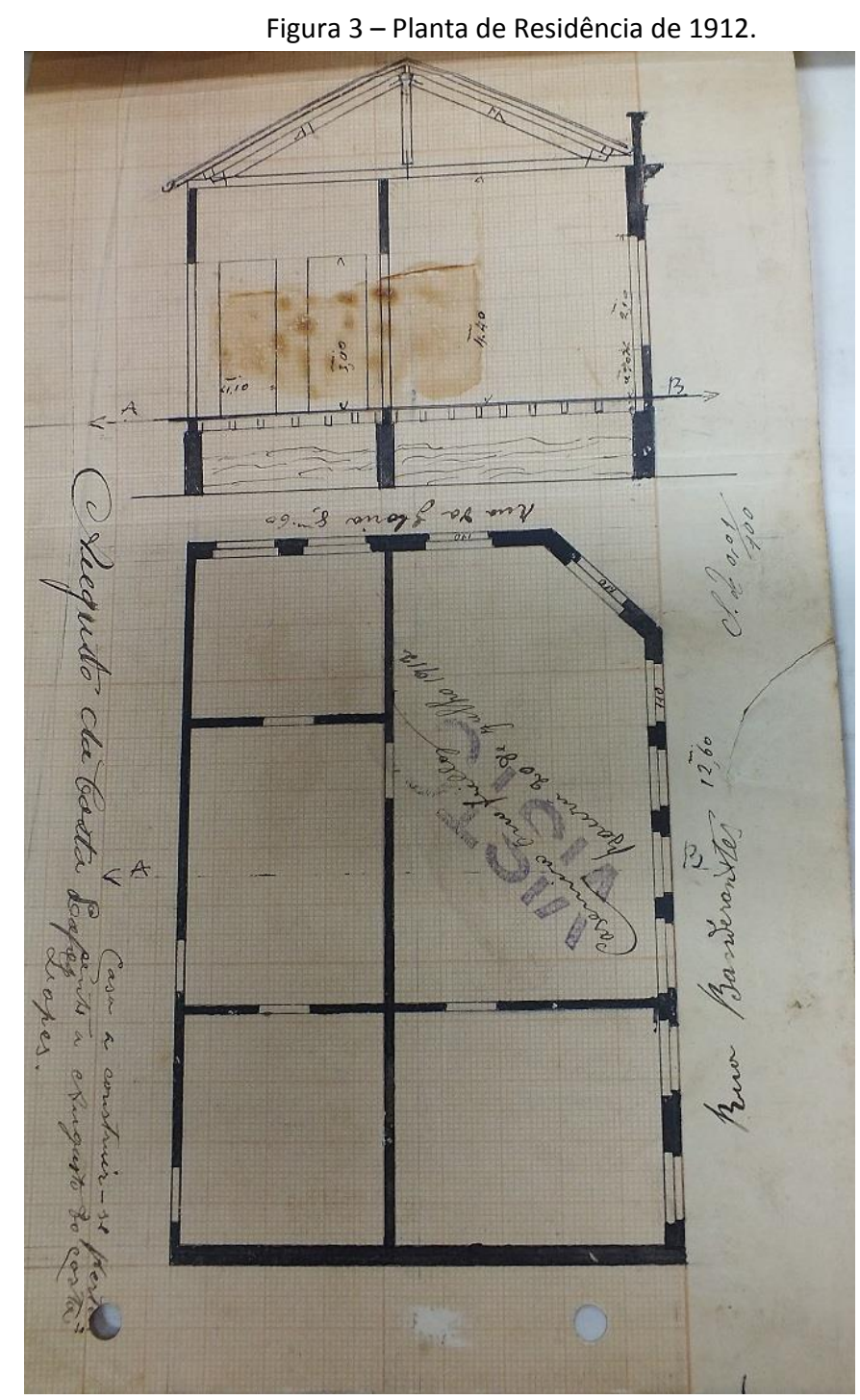

Fonte: arquivo SEPLAN -Prefeitura de Bauru), 2015.

Bauru se tornava importante entroncamento, transformando-se em pólo regional, favorecendo o comércio, a prestação de serviços e seu crescimento. Toda essa mudança em tão poucos anos impôs um rápido e inesperado crescimento populacional e com ele a falta de higiene na cidade, juntamente com as doenças. Na medida em que a cidade crescia as discussões políticas se voltavam para uma nova área de ação. Medidas sanitárias precisavam ser tomadas para resolver estas questões.

\section{3 ÁGUA E ESGOTO}

Os jornais de época publicavam o problema do saneamento da cidade e o descaso do poder público frente as necessidades da população com relação ao abastecimento de água e esgotamento sanitário: 


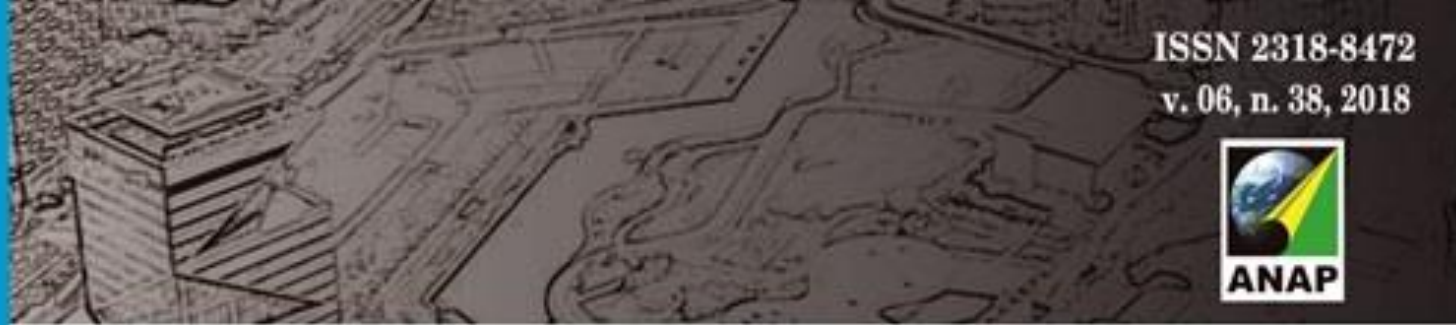

Gerenciamento de Cidades

Em todas as cidades novas, a primeira necessidade a qual os poderes administrativos prestam a máxima atenção, e o melhor apoio é ao fornecimento de agua e a rede de esgotos; porém em Bauru não se pensa em tal. (O BAURU, 1910) ${ }^{3}$

Apenas em 1910 é que os serviços de água e esgoto são oferecidos à população, quando o prefeito municipal Álvaro de Sá, reconhecendo a necessidade de se cuidar da saúde pública, até mesmo devido a sua formação como médico higienista, preocupou-se em contratar projeto para instalar rede de água e esgotos.

O aumento incessante da população - devido à implantação das ferrovias - e o crescimento gerando construções de centenas de moradias, que faziam uso de variados sistemas de captação de água e praticamente a mesma quantidade de fossas sépticas, requeriam este tipo de saneamento e infraestrutura básica. (PELEGRINA, 1991).

O engenheiro da Companhia Estrada de Ferro Noroeste, Silvio Saint Martin, estudou e projetou o primeiro serviço de água da cidade, que foi instalado nas cabeceiras do Córrego das Flores (onde atualmente encontra-se o anfiteatro Vitória Régia).No entanto a população crescia e as medidas sanitaristas não acompanhavam a demanda, além de não atingirem toda a comunidade. Os menos favorecidos, na maioria das vezes trabalhadores da ferrovia, que não podiam pagar pelos serviços, adoeciam, contaminados pela água sem tratamento.

Toda infraestrutura executada pela iniciativa privada terá como fim o lucro, característica típica de qualquer outro serviço oferecido pelo capitalismo. Portanto, só terá acesso a ela aqueles que puderem paga-la. Desta forma, apenas alguns setores urbanos, especialmente as áreas mais nobres, serão beneficiadas pela melhoria. (GHIRARDELLO, 1992)

Em 5 de dezembro de 1911, no Jornal O BAHURU, tem-se a seguinte nota sobre os serviços de água que estavam sendo implantados:

[...] a zona servida pela rede é constituída pelo triangulo incluído entre as estações de ferro Sorocabana, Noroeste e paulista, Rua Araujo Leite e Avenida Alfredo Maia, triangulo este que fica considerado como zona central, e beneficiado em todos os outros melhoramentos projetados.

$O$ resto da cidade atualmente não ficará contemplado nesses serviços além dos chafarizes necessários ao abastecimento d'agua na parte alta da cidade. (O BAHURU, 1911) ${ }^{4}$

É notório que a implantação da rede de água tinha estreita relação com os interesses da ferrovia e de uma pequena parcela da população privilegiada - a elite dominante. A infraestrutura urbana e o saneamento vêm, neste período, favorecer apenas as camadas mais ricas da população.

\footnotetext{
${ }^{3}$ Ver Jornal O Bauru de 8 de maio de 1910.

${ }^{4}$ A transcrição do texto foi realizada da forma como o artigo se encontra escrito no jornal, por isso a grafia rebuscada.
} 


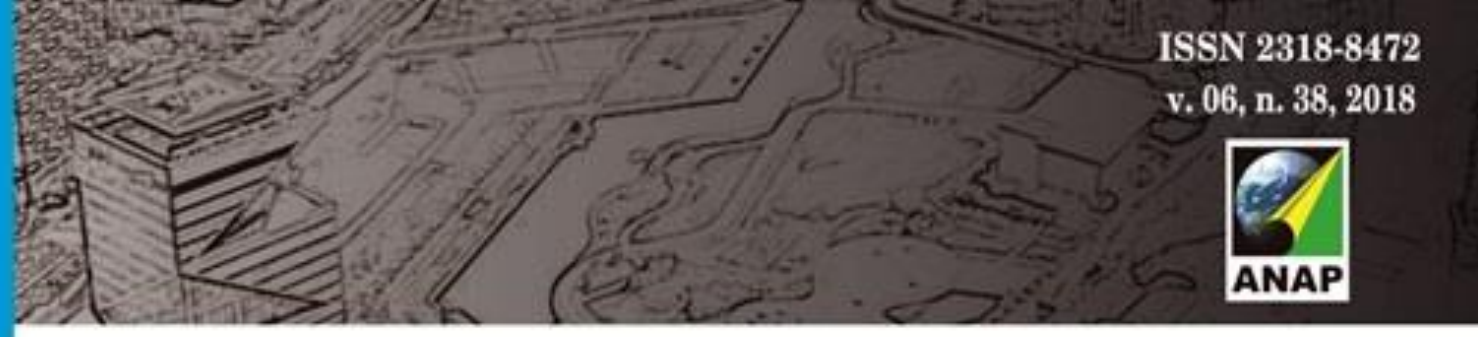

Gerenciamento de Cidades

Figura 4: Utilização de Poços Artesianos

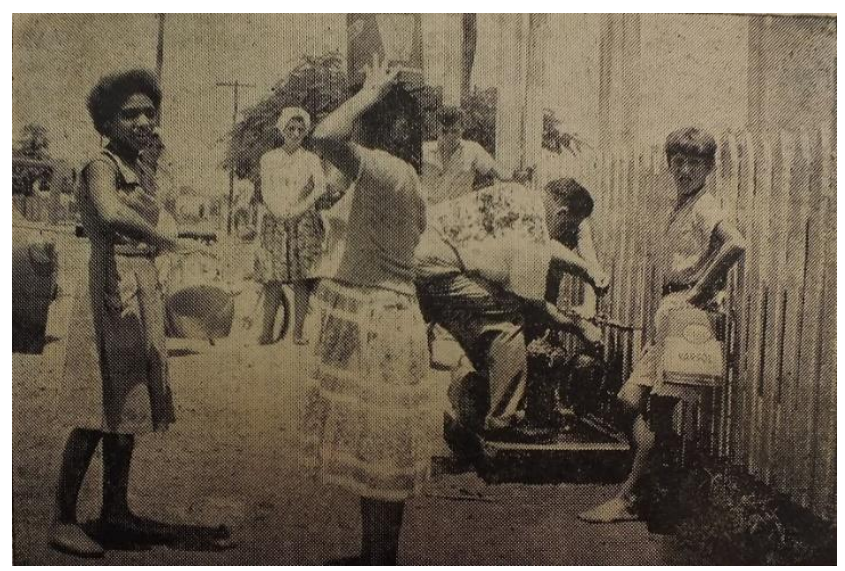

Figura 5 - Bebedouros para animais próximo à estação da paulista

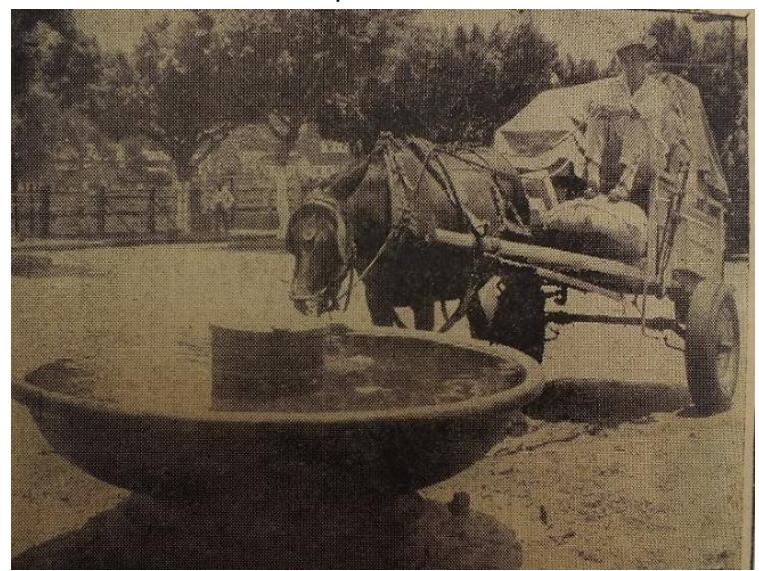

Fonte: Nuphis - Universidade Sagrado Coração (USC), 2013

A figura 4, mesmo que mais recente, mostra famílias inteiras que se locomoviam até o poço artesiano situado na antiga fábrica da Anderson Clayton a fim de buscarem água. Observa-se a utilização de latas, garrafões, moringas e litros. A população que não era contemplada com os serviços de abastecimento, através de rede canalizada tinha que buscar água em outros lugares. Na figura 5 tem-se a imagem de um bebedouro, ou seja, tanques de águas para saciar a sede dos cavalos. Com o progresso estes tanques foram sendo retirados. Em Bauru havia dois: um localizava-se na Praça Gomes de Araújo e o outro em frente à velha estação da Paulista. ${ }^{5}$

Apesar do atraso dos vereadores na implantação da canalização, é finalmente inaugurado, na gestão do prefeito Major José Carlos de Freire Figueiredo, em 1912, o sistema de abastecimento de água e esgotamento sanitário na cidade, que passou a utilizar as águas das nascentes do Córrego das Flores e do Ribeirão Bauru (GHIRARDELLO, 2002; PELEGRINA, 1991). A Empresa que passou a cuidar destes serviços foi a Companhia de Águas e Esgotos de Bauru, onde por meio da Lei no 45, ficou assegurado de concessão e privilégios na execução e gerenciamento destes serviços no prazo de 30 anos ao Coronel Andrade.

A lei outorgada, em 23 de agosto de 1912, para exploração de água e esgoto, em seu artigo 5o, informava que a partir da implantação do sistema, a municipalidade iria transferir ao concessionário todas as instalações públicas feitas nas redes até aquela data, incluindo os mananciais, terrenos e servidões, além do direito de desapropriações necessárias para o funcionamento dos serviços. Desta forma, percebemos que tanto a prefeitura quanto a câmara estavam isentas de responsabilidades, ficando a cargo da Companhia de Água e Esgoto de Bauru.

Para a eficiência e realização satisfatória destes serviços, a câmara municipal tornou obrigatória a adoção dos serviços de água e esgoto em todos os prédios servidos pelas redes mestras, "começando as taxas a serem cobradas imediatamente que for assentado o ramal até o alinhamento dos passeios dos prédios"

\footnotetext{
${ }^{5}$ Artigo publicado em jornal não identificado no período de janeiro de 1945 a dezembro de 1970. Tal material se encontra no Núcleo de Pesquisa Histórica da Universidade Sagrado Coração - NUPHIS - USC
} 


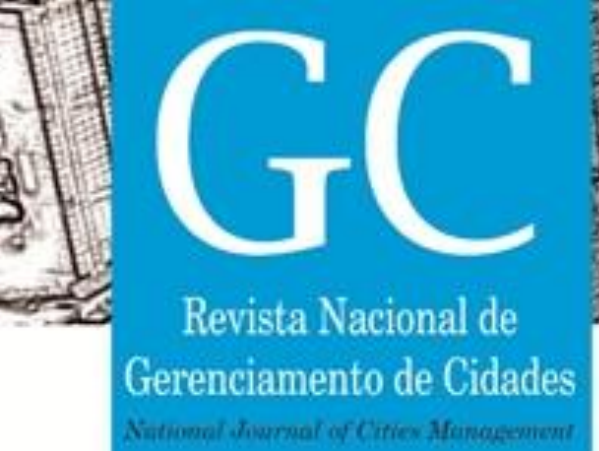

Com a instalação das primeiras redes de abastecimento de água e coleta de esgoto, houve uma mudança de conceito quanto ao modo de viver e morar.

\begin{abstract}
A essas transformações no campo da arquitetura correspondiam modificações significativas nos equipamentos das cidades. Transpondo uma etapa de aperfeiçoamento tecnológico, as cidades equiparam-se com redes de esgotos, de abastecimento de água, iluminação e de transportes coletivos. (REIS FILHO, 1987, p. 50).
\end{abstract}

Além disso, para Reis Filho (1987), o aperfeiçoamento dos hábitos higiênicos coincidia com a instalação dos primeiros banheiros com água corrente e com o aparecimento das venezianas.

O encanamento hidráulico e o surgimento do banheiro com água corrente e esgoto tornaram-se comuns nas casas paulistas do final do século XIX (LEMOS, 1972). Importante ressaltar que a primeira planta, encontrada nos arquivos da prefeitura de Bauru, na qual há existência do banheiro no corpo da casa, é datada de 1912.

Figura 7 - Detalhe da Planta de Residência de 1912 com Banheiro.

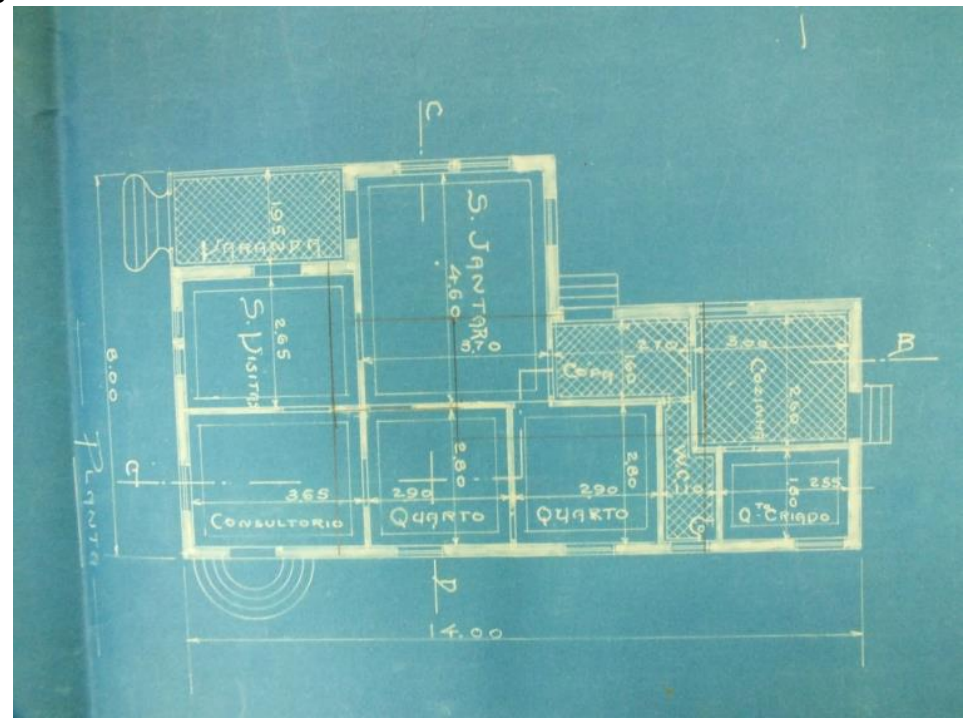

Fonte: arquivo Prefeitura Municipal de Bauru

A figura 7 retrata a planta da residência intitulada Villa Dr. Goyanna, de 1912, contém as dimensões da área construída, localização dos cômodos com cotas internas, identificação das áreas molhadas e varanda com pisos diferenciados, aberturas, escadas. Outro ponto interessante é a presença de um quarto para criado. Não foram encontrados dados do local da obra. Certamente tratava-se de uma residência de elite, devido sua dimensão, cuidadoso detalhamento e a denominação de "Villa", nos desenhos ficam expressos os tipos de piso, sendo nos ambientes úmidos utilizados pisos frios, provavelmente ladrilho hidráulico e nos demais assoalho de madeira. Também se percebe nos cortes a utilização de azulejos, à meia altura, na cozinha e banheiro. Com relação as peças gráficas, apresenta fachada, planta, planta de cobertura e 2 cortes. 
Percebe-se novamente no discurso higienista, a dialética entre saúde e infraestrutura, mostrando como a ausência destes serviços afetavam o cotidiano da população. Claro que a solução para a área central estava chegando, não de forma imediata. As redes já estavam sendo implantadas, no entanto seriam necessários alguns anos para a implementação satisfatória desta infraestrutura.

As políticas sanitárias, o higienismo e os pensamentos embelezadores são consolidados na forma de lei com o Código de Postura de 1913, quando apareceu, pela primeira vez, um capítulo dando diretrizes normativas sobre água e esgoto.

Logo no primeiro artigo do capítulo 5, o no 66, podemos observar a obrigatoriedade das ligações de água de abastecimento na rede geral, onde há a canalização nas ruas. Caso não fosse efetuada a ligação, o proprietário da edificação seria multado:

É obrigatório o suprimento d'água pela rede geral do abastecimento para todos os prédios situado na área atravessada pelo encanamento geral. Pena de $30 \$ 000$ e na reincidência o dobro, sendo o prédio interditado (Código de Postura, 1913).

A questão do esgotamento sanitário é tratada no artigo 71 , em que se normatiza que em todas as casas, ruas e quintais por onde passassem os coletores de esgotos seria "obrigatória a instalação dos respectivos aparelhos de coleta e sua ligação a rede geral".

Ainda sobre o esgoto, no artigo 72, temos que: "Fica expressamente proibida a construção, mesmo dentro de quintais comuns, de obras de esgotos de qualquer natureza, as quais só podem ser executadas sob a fiscalização da Prefeitura. Penas, as mesmas do artigo 66".

Para as ligações dos ramais, era necessário providenciar um requerimento ao prefeito e, cada lote possuiria apenas uma ligação, sendo proibidas as internas, de um prédio para o outro. Outro ponto importante, que tratava a lei, diz respeito as despesas de material para assentamento de canos e demais materiais, juntamente com a mão de obra de instalação, que ficaria por conta do requerente da rede. Neste período a cobrança da água era realizada em relação ao valor locativo de cada prédio contribuinte ${ }^{6}$ e não pelo consumo de cada lote, como cobrado atualmente.

Além disto, o fornecimento do líquido era baseado em especificação do Código Sanitário Estadual, de 1894, em que normatizava o fornecimento de água para as cidades: para uma população com até 10 mil habitantes, 100 litros/dia/pessoa, para população acima de 10 mil habitantes, 150 litros/dia/pessoa, no caso de mais de 50 mil habitantes, 200 litros/dia/pessoa. Hoje, estes serviços de ligação, material empregado e mão de obra, são de responsabilidade do Departamento de Água e Esgoto de Bauru(DAE). Embora os códigos de posturas vigentes e medidas saneadoras incluíssem a presença dos banheiros, encontramos na data de 1915 exemplar de projeto de moradia para aprovação sem a presença do mesmo. Importante ressaltar que o logradouro do edifico já se encontrava em área com acesso a rede de água e esgotamento sanitário. Consta que o proprietário Domingos Gimenes solicita aprovação com o desenho indicado na figura 9. Nas peças gráficas verifica-se a fachada com riqueza de detalhes e planta muito básica.

\footnotetext{
${ }^{6}$ De acordo com a lei 45 de 23 de agosto de 1912, no artigo 13 "para efeito de cobrança das taxas são considerados prédios contribuintes toda e qualquer habitação independente, verificando-se essa independência ou pelo fogão ou pelo aluguel".
} 


\section{CONSIDERAÇÕES FINAIS}

Há questão com relevada importância ao longo da história da humanidade, tais como abastecimento de água e coleta de esgoto. Ao mesmo tempo é uma lição sobre os preceitos do saneamento para o exercício de diversas atividades.

O desenvolvimento urbano da cidade de Bauru teve como agente propulsor a ferrovia, que viabilizou, expandiu e urbanizou a urbe. Dentro de seus contextos e escalas, Bauru era resultado de transformações de seu espaço urbano em busca de saneamento e modernização. A infraestrutura de água e esgoto foram importantes neste processo. Os preceitos higienistas, $\mathrm{O}$ avanço das técnicas construtivas, a instalação do sistema de abastecimento de água e instalação de redes de coleta de esgoto redefiniram o panorama da arquitetura local. O poder público passou a gerencias o espaço urbano, por meio da criação de legislação e todo aparato técnico. Assim, os estudos das plantas nos mostraram formas de morar de uma época.

Buscamos reflexões na compreensão da modernização, saneamento e estética na cidade, sendo estruturada por ações de melhoramentos, embelezamentos e higienistas. Intervenções pontuais, norteadas pelos Códigos de Posturas e demais legislações, desde a implantação das ferrovias nos anos de 1910, foram necessárias para consolidar o processo de modernização de Bauru. O saneamento, pelo viés do abastecimento de água e esgotamento sanitário, contribuiu para esta legitimação e produção das construções voltadas para o morar.

\section{REFERÊNCIAS}

CHALHOUB, Sidney. Cidade Febril: Cortiços e Epidemias na Corte Imperial. São Paulo: Companhia das Letras, 2006.

CONSTANTINO, Norma Regina Truppel. A construção da paisagem de fundo de vale: o caso de Bauru. Tese doutorado: FAUUSP. São Paulo, 2005.

GHIRARDELLO, Nilson. Aspectos do direcionamento urbano da cidade de Bauru. 187 f. Dissertação (Mestrado em Arquitetura) - Escola de Engenharia de São Paulo, 1992.

1900). São Paulo: UNESP,

A Formação dos patrimônios religiosos no processo de expansão urbana paulista (1850-

LEMOS, Carlos Alberto Cerqueira. Cozinhas, etc: um estudo sobre as zonas de serviço da casa paulista. Tese (Doutorado) FAUUSP. São Paulo, 1972.

PELEGRINA, Gabriel. Ruiz E ZANLOCHI, Terezinha. Santarosa. Ferrovia e Urbanização: o caso de Bauru. Bauru: Universidade do Sagrado Coração, 1991.

REIS FILHO, Nestor Goulart. Quadro da arquitetura no Brasil. São Paulo: Editora Perspectiva, 2000.

SANT'ANNA, Denise Bermuzzi. Cidade das águas: usos de rios, córregos, bicas e chafarizes em São Paulo (1822-1901). São Paulo: Senac, 2007.

SILVA, Alcides. Roteiro Histórico: Uma cidade e uma Instituição. Bauru: Tipografia Comercial, 1957. 